E-MAIL CONTRIBUTIONS

\title{
'Failings' of the academic system are a symptom - not a cause
}

JIM LEMON

Having read the formal and email contributions to this debate, I felt that there might be what I call an "event focus" in the analyses. It is quite common for this to occur; traffic safety is analyzed on the basis of crashes, health on the occurrence of disease and my own field, mental function on the basis of dysfunction. Of course, the study of pathological events is valuable, but it often leads to outcome-related functions being mistaken for causal ones.

The majority of individuals do not become scientists. Indeed, even in societies in which acquiring a scientific education is not particularly difficult, only a minority of adults can plausibly call themselves scientists. So perhaps the first question that might be asked is, "If science is so good, why aren't more people doing it?" Obviously, this relates to Nelson's contribution, in which it is claimed that the educational system in the USA is biased toward an oversupply of scientists. Whether or not this true, most children do not perceive science, or for that matter, higher education, as a sufficiently attractive activity to pursue it.

This does not apply purely to females. All young people assess the available options and decide which are most attractive. Clearly, pursuing a career of which higher education is a major component is not an overwhelmingly popular choice. As countless depictions of "the nerd" remind us, education and knowledge may not do us much good in "real life" unless we make an economic success of it. However, it would be a mistake to attempt to glamorize science or education. Rather, I would argue that any career is a succession of choices, and typically involves tension between the career and the private (or "real") life of the individual.

Several of the contributors, such as Krummacher and Scheermeyer mention the most obvious of these, child-bearing and raising. Using this as an example, I would suggest that decisions concerning child-bearing and raising begin to be made early in a child's life. Not only tentative decisions to pursue this, but also behavioral orientations consistent with it. If these behavioral orientations are incompatible with scholastic achievement, it is unlikely that the young person will be able to effectively pursue both. To go beyond the example, "real life", the acquisition of friends, relationships, entertainment, etc., is somewhat different from the structured world of academic success, and as any academic knows, the two often conflict.

I would suggest that one major reason that women have a harder job in pursuing academic careers is that their "real life" roles generate substantially more conflict with their careers than do those of men. This is certainly a commonplace in the ambit of the present debate, but its scope is often considered too narrowly. To apply the standards of academic institutions to the consideration of the myriad "real life" choices made is as misguided as the application of jurisprudence to the "real life" mayhem of self-defence. The attempt to represent the difficulties faced by female (or male) scientists across their lives as failings of the academic institutions which are embedded in the larger matrix of society may well be treating the symptom.

\author{
Jim Lemon \\ Health Psychology \\ UTS, Australia \\ jimlemon@uts.edu.au
}


Nature @ Macmillan Publishers Ltd 1999 Registered No. 785998 England. 